Check for updates

Cite this: Mater. Adv., 2021, 2, 5955

Received 11th June 2021 Accepted 27th July 2021

DOI: $10.1039 / \mathrm{d} 1 \mathrm{ma} 00510 \mathrm{c}$

rsc.li/materials-advances

\title{
Electronic properties and high-pressure behavior of wolframite-type $\mathrm{CoWO}_{4} \dagger$
}

\author{
Enrico Bandiello, (D) *a Plácida Rodríguez-Hernández, (D) ${ }^{b}$ Alfonso Muñoz, (D) ${ }^{b}$ \\ Manuel Bajo Buenestado, (D) ${ }^{a}$ Catalin Popescu (D) ${ }^{c}$ and Daniel Errandonea (D) ${ }^{a}$
}

\begin{abstract}
In this work we characterize wolframite-type $\mathrm{CoWO}_{4}$ under ambient conditions and under compression up to $10 \mathrm{GPa}$, with emphasis on its electronic structure. X-Ray diffraction and vibrational experiments, supported by ab initio calculations, show that $\mathrm{CoWO}_{4}$ is stable under high-pressure conditions, as no structural changes are detected in the studied pressure range. Interesting findings come from optical absorption spectroscopy. On the one hand, $\mathrm{CoWO}_{4}$ is confirmed to have one of the lowest band gaps among similar wolframites, around $2.25 \mathrm{eV}$. This makes $\mathrm{CoWO}_{4}$ suitable for use in applications such as the photocatalysis of organic pollutants and water splitting. Additionally, a monotonic decrease of the band gap is found upon compression. This phenomenon is seldom observed in $\mathrm{AWO}_{4}$ wolframites and is attributed to the open character of the $d$ shell of $\mathrm{Co}^{2+}$. Our results are supported by theoretical $a b$ initio simulations and are discussed with reference to other wolframites.
\end{abstract}

\section{Introduction}

$\mathrm{AWO}_{4}$ wolframites, where $\mathrm{A}$ is a divalent metallic cation, are crystalline compounds mainly studied for their optical properties. Depending upon the divalent cation, they may crystalize in a tetragonal structure known as scheelite or in a monoclinic structure known as wolframite. ${ }^{1}$ Many of these compounds have multiple technological applications. They are, in fact, luminescent and scintillating materials, and are employed in high-energy physics for the detection of $\gamma$ and $\mathrm{X}$ photons, in fluorescent devices, as dielectric ceramics in microwave applications and fiber optics. ${ }^{2-5} \mathrm{AWO}_{4}$ wolframites have also been proposed for use in sensors for gases or nitric acid ${ }^{6,7}$ and some of them, among which $\mathrm{ZnWO}_{4}$ and $\mathrm{CoWO}_{4}$, have shown promising performances in the photodegradation of organic pollutants. $^{8,9} \mathrm{CoWO}_{4}$ has also interesting magnetic properties. $^{10}$ Monoclinic wolframite-type compounds share the same crystal structure (space group $P 2 / c$ ) and generally are semiconductors with energy gaps, $E_{\mathrm{g}}$, covering from the near-ultraviolet to the visible. ${ }^{11}$

Among wolframites, $\mathrm{CoWO}_{4}$ has been one of the less studied compounds, even if it has recently started to get attention

\footnotetext{
${ }^{a}$ Departamento de Física Aplicada-ICMUV, MALTA Consolider Team, Universidad de Valencia, Edificio de Investigación, C/Dr Moliner 50, Burjassot, 46100 Valencia, Spain. E-mail: enrico.bandiello@uv.es

${ }^{b}$ Departamento de Física, Instituto de Materiales y Nanotecnología, MALTA Consolider Team, Universidad de La Laguna, Tenerife E38205, Spain ${ }^{c}$ CELLS-ALBA Synchrotron Light Facility, Cerdanyola del Valles, 08290 Barcelona, Spain

$\dagger$ Electronic supplementary information (ESI) available. See DOI: 10.1039/d1ma00510c
}

mainly because of its low band gap (2.3-2.7 eV), which makes it a good candidate for green technologies, in particular as a photocatalyst for degradation of pollutants present in water or for the production of hydrogen fuel by means of water splitting. ${ }^{12-17}$ For these environmentally friendly applications, an accurate knowledge of the electronic properties of $\mathrm{CoWO}_{4}$ is important. In particular, the band-gap energy of $\mathrm{CoWO}_{4}$ has not yet been measured by optical-absorption spectroscopy. Some applications of $\mathrm{CoWO}_{4}$ involve extreme environments, in particular at high pressure, and it is thus important to accurately characterize the influence of high pressure on the structural, vibrational, and optical properties of $\mathrm{CoWO}_{4}$.

In this work, we focus our attention on wolframite-type $\mathrm{CoWO}_{4}$. Characterizing it under ambient and high-pressure conditions, we have determined the structural stability of $\mathrm{CoWO}_{4}$ up to at least $10 \mathrm{GPa}$, as all relevant physical magnitudes are found to vary smoothly in the studied pressure range. Structural and vibrational properties of $\mathrm{CoWO}_{4}$, such as its bulk modulus and its anisotropic compressibility, are found to be compatible with those of analogue wolframites, along with its Raman phonons and their evolution under compression. On the other hand, interesting results come from the analysis of the optical absorption spectra. In fact, we could state that $\mathrm{CoWO}_{4}$ is among the wolframites with the lowest band gap, $E_{\mathrm{g}}=2.25(1) \mathrm{eV}$. Additionally, the band gap is shown to steeply decrease under compression, something unusual for $\mathrm{AWO}_{4}$ wolframites and that has been reported only for $\mathrm{MnWO}_{4}$ so far. We discuss these results on the basis of theoretical simulations and by comparison with $\mathrm{MnWO}_{4}\left(E_{\mathrm{g}}=2.37 \mathrm{eV}\right) .{ }^{18} \mathrm{We}$ have found that the contribution of unfilled $\mathrm{Co}^{2+} 4 \mathrm{~d}$ states to both 
the top of the valence band and the bottom of the conduction band is responsible for the low band gap of $\mathrm{CoWO}_{4}$ and its negative dependence on pressure. These findings are important from the point of view of the potential application of $\mathrm{CoWO}_{4}$, as tunable low band-gap compounds may be useful in photodegradation appliances. Also, they are likely to stimulate new research in the field of the electronic structure of $\mathrm{AWO}_{4}$ wolframites, as significant trends are expected to be established linking the electron configuration of the $\mathrm{A}$ atom and the behavior of the band gap of these compounds.

\section{Experimental details}

$\mathrm{Na}_{2} \mathrm{WO}_{4}$ and anhydrous $\mathrm{CoCl}_{2}$ obtained from Alfa Aesar (purity $>99 \%$ ) were used as precursors for the preparation of $\mathrm{CoWO}_{4}$. Stoichiometric quantities of the reactants were weighed, and the mixture was ground in an agate mortar with the addition of ethanol. The product was washed with distilled water to remove sodium chloride. Subsequently, it was heated at $500{ }^{\circ} \mathrm{C}$. XRD measurements at ambient pressure were taken with the sample in the powder form using $\mathrm{Cu} \mathrm{K}_{\alpha}$ radiation $(\lambda=1.5406 \AA)$, confirming that the obtained product was $\mathrm{CoWO}_{4}$, with no detectable minority phases or impurities. High-Pressure (HP) XRD experiments, of up to around $10 \mathrm{GPa}$, were performed at the MSPD beamline of ALBA Synchrotron ${ }^{19}$ using a Diamond Anvil Cell (DAC) loaded with $\mathrm{CoWO}_{4}$ in the powder form. The culets of the diamond had a diameter of $500 \mu \mathrm{m}$ The sample was deposited in the hole of a pre-indented stainless-steel gasket (diameter $200 \mu \mathrm{m}$ ), together with ruby chips for the determination of the pressure through the ruby-fluorescence $\operatorname{method}^{20}$ and a methanol: ethanol: water (MEW) mixture in the $16: 3: 1$ volume ratio as the pressure-transmitting medium (PTM). 2D diffraction images were taken on a Rayonix CCD detector, using a wavelength $\lambda=0.4246 \AA$ and transformed to intensity-2 $\theta$ patterns using DIOPTAS. ${ }^{21}$ Rietveld and Le Bail fits were performed using POWDER CELL. ${ }^{22}$ The Equation of State (EOS) of $\mathrm{CoWO}_{4}$ was calculated by fitting a 2nd order BirchMurnaghan EOS to the pressure-volume data obtained from the HP experiments. Structure drawing and bond length measurements were performed with VESTA. ${ }^{23}$

HP optical absorption experiments in the UV-vis range were performed on a pre-compressed pellet of $\mathrm{CoWO}_{4}$ loaded in a DAC (similarly to what was done for HP XRD). Two light sources, an UV and a deuterium lamp were used. Absorption spectra were measured by comparing, at each pressure point, the spectrum of the light source through the pressure transmitting medium and through the sample ("sample-in, sample-out method").

Raman spectroscopy was performed with a powder sample in a DAC, loaded similarly to the DACs used for HP XRD and UV-vis spectroscopy. Raman spectra were collected in the backscattering geometry using a He-Ne laser $(\lambda=632.8 \mathrm{~nm})$, a JOBIN-YVON TRH1000 spectrophotometer, an edge filter, and a thermoelectrically cooled multichannel CCD (HORIBA SYNAPSE) as the detector.

\section{Theoretical simulations}

The simulations of the structural, electronic, dynamical, and elastic properties were carried out using density functional theory (DFT) ${ }^{24}$ and the VASP (Vienna $A b$ initio Simulation Package) package. ${ }^{25,26}$ We use the pseudopotential method with the projector augmented wave (PAW) scheme, ${ }^{27}$ using a plane-wave cutoff of $540 \mathrm{eV}$ to ensure high accurate convergence. The k-point integration in the Brillouin zone (BZ) was done using a big sampling of $6 \times 6 \times 6$ grid for the primitive unit cell. Generalized Gradient Approximation, GGA with the Perdew, Burke, and Ernzerhof for solids, PBEsol prescription for the exchange-correlation energy. ${ }^{28}$ Besides, we perform our simulations with the DFT $+U$ scheme of Dudarev et al. ${ }^{29}$ to treat the strongly correlated states of Co and $\mathrm{W}$ atoms by means of a single effective parameter, $U_{\text {eff }}=U-J$, where $U$ and $J$ are the screened Coulomb and exchange parameters. The selected values of $U_{\text {eff }}$ were 3.32 and $6.2 \mathrm{eV}$, for the Co and $\mathrm{W}$ atoms, respectively. ${ }^{30}$ The antiferromagnetic configuration was found to have the lowest energy. The cell parameters and the atomic positions are relaxed to obtain the optimized configurations for a given volume, where the atomic forces were less than $0.004 \mathrm{eV}^{-1}$, and the stress tensor is diagonal with an accuracy of less than $0.1 \mathrm{GPa}$. This procedure allows us to obtain a set of volume, energy, and pressure data from our simulations.

Phonopy package ${ }^{31}$ was used to perform lattice-dynamics calculations. The frequencies, and the eigenvectors of the normal vibration modes were determined at $\Gamma$ point. The elastic properties were computed employing the method implemented in the VASP code. ${ }^{32,33}$ These elastic constants are obtained for the fully optimized structures by small deformations, which produce small strains in different directions taking into account the structure symmetry. ${ }^{33}$ The electronic band structure along the high symmetry directions of the first BZ were obtained using the relaxed theoretical structures at different pressures.

\section{Results and discussion}

\section{XRD experiments}

As described above, wolframite-type $\mathrm{CoWO}_{4}$ crystallizes naturally in a monoclinic structure belonging to the $P 2 / c$ space group (S.G. 13, $Z=2$ ). The ambient-pressure XRD pattern for $\mathrm{CoWO}_{4}$, together with the Rietveld fit, is shown in Fig. 1. All the XRD peaks are correctly indexed in the $P 2 / c$ space group. Atomic positions, as calculated by us through theoretical simulations, are compatible with the values given in the literature $^{34}$ (see comparison in Table 1) and have been not refined in our fits. Cell parameters as obtained by XRD in open air are $a=4.670(5) \AA, b=5.687(6) \AA, c=4.951(5) \AA, \beta=90.08(9)^{\circ}$ (volume $V=131.5(2) \AA^{3}$ ), in good agreement with those measured using neutron diffraction (ref. 34) and those obtained by $a b$ initio simulations (Table S1, ESI $\dagger$ ). According to these data, the structure of wolframite-type $\mathrm{CoWO}_{4}$ can be described as a distorted hexagonal packing of $\mathrm{O}$ atoms in which Co and $\mathrm{W}$ both are 6-fold coordinated with oxygens. The coordination 


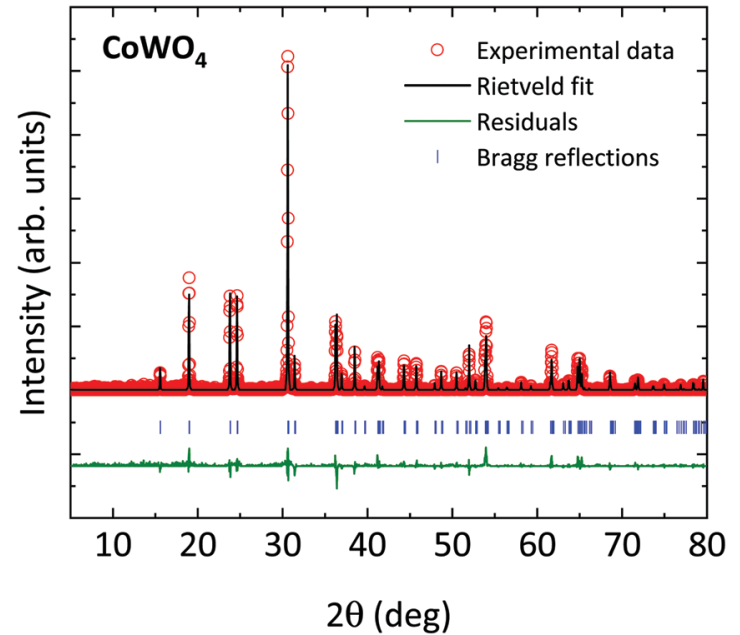

Fig. 1 Ambient-pressure XRD pattern for $\mathrm{CoWO}_{4}$, as obtained by a powder sample in open air $(\lambda=1.1 .5406 \AA)$ and Rietveld fit. Red circles: experimental data; black line: Rietveld fit; green line: residuals; blue ticks: Bragg reflections.

Table 1 Atomic positions for wolframite-type $\mathrm{CoWO}_{4}$, from ref. 34, and comparison with theoretical values from ab initio simulations (in parentheses)

\begin{tabular}{lllll}
\hline Atom & Wyckoff & $x / a$ & $y / b$ & $z / c$ \\
\hline Co & $2 f$ & $1 / 2$ & $0.6712(8)$ & $1 / 4$ \\
& & & $(0.65955)$ & \\
$\mathrm{W}$ & $2 e$ & 0 & $0.1773(4)$ & $1 / 4$ \\
& & & $(0.17883)$ & \\
$\mathrm{O}_{1}$ & $4 g$ & $0.2176(3)$ & $0.1080(4)$ & $0.9321(3)$ \\
& & $(0.22012)$ & $(0.10863)$ & $(0.92811)$ \\
$\mathrm{O}_{2}$ & $4 g$ & $0.2540(3)$ & $0.3757(4)$ & $0.3939(3)$ \\
& & $(0.26102)$ & $(0.38128)$ & $(0.40212)$
\end{tabular}

octahedral units $\mathrm{CoO}_{6}$ and $\mathrm{WO}_{6}$ share two edges with neighboring polyhedra of the same type, forming alternating chains of identical octahedra along the [001] axis (Fig. 2a and b). Besides, these polyhedra are slightly irregular, as the bond lengths $\mathrm{Co}-\mathrm{O}$ and $\mathrm{W}-\mathrm{O}$ are not all equal (Table 2).

The evolution of the XRD patterns of $\mathrm{CoWO}_{4}$ under compression in nearly hydrostatic conditions ${ }^{35}$ is summarized in a)

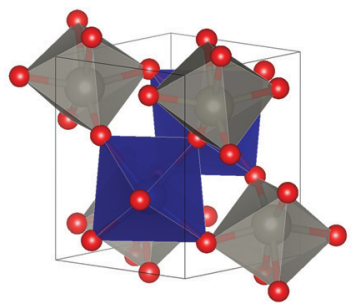

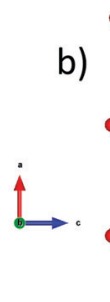

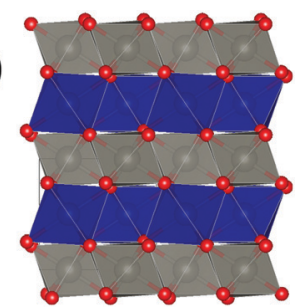

Fig. 2 (a) Ambient-pressure structure of wolframite-type $\mathrm{CoWO}_{4}$. Red, blue, and grey spheres are respectively oxygen, cobalt, and tungsten atoms. The coordination polyhedra of tungsten and cobalt are shown in blue and grey, respectively; (b) projection of wolframite-type $\mathrm{CoWO}_{4}$ unit cell onto the (010) plane, showing the alternate chains of $\mathrm{CoO}_{6}$ and $\mathrm{WO}_{6}$ octahedra along [001].
Table 2 Bond distances $d$ in the $\mathrm{CoO}_{6} \mathrm{WO}_{6}$ octahedra of $\mathrm{CoWO}_{4}$ and their volume $V$ at ambient pressure

\begin{tabular}{llll}
\hline Bond & Multiplicity & $d(\AA)$ & $V\left(\AA^{3}\right)$ \\
\hline $\mathrm{Co}-\mathrm{O}_{1}$ & 2 & $2.033(4)$ & 12.1456 \\
$\mathrm{Co}-\mathrm{O}_{2}$ & 2 & $2.1198(18)$ & \\
$\mathrm{Co}-\mathrm{O}_{2}$ & 2 & $2.157(5)$ & \\
$\mathrm{W}-\mathrm{O}_{1}$ & 2 & $2.1164(4)$ & 9.3647 \\
$\mathrm{~W}-\mathrm{O}_{1}$ & 2 & $1.916(3)$ & \\
$\mathrm{W}-\mathrm{O}_{2}$ & 2 & $1.785(3)$ &
\end{tabular}

Fig. 3. As shown, all the patterns up to $9.5 \mathrm{GPa}$ can be indexed in the same $P 2 / c$ space group. The shrinking of the unit cell is pointed out by the progressive shifting of the Bragg reflections towards higher values of $2 \theta$. Apart from this, the only notable change in the patterns is the splitting of some peaks, which is more evident in the $8-10^{\circ}$ angular range. These splitting are due to the variation of the $\beta$ angle of the monoclinic structure, which is initially very close to $90^{\circ}$ and increases with a positive pressure coefficient of $\partial \beta / \partial P=0.088(4)$ deg $\mathrm{GPa}^{-1}$ (Table 3 and Fig. 4). At ambient pressure, the most intense diffraction peak is an overlap of the (111) and (111) reflections (at $8.34^{\circ}$ and $8.35^{\circ}$, respectively); these appear clearly separated at $9.5 \mathrm{GPa}$. Similarly, the (002) and (021) peaks $\left(9.84^{\circ}\right.$ and $9.88^{\circ}$ at ambient pressure), which are strictly convoluted at low pressure, greatly

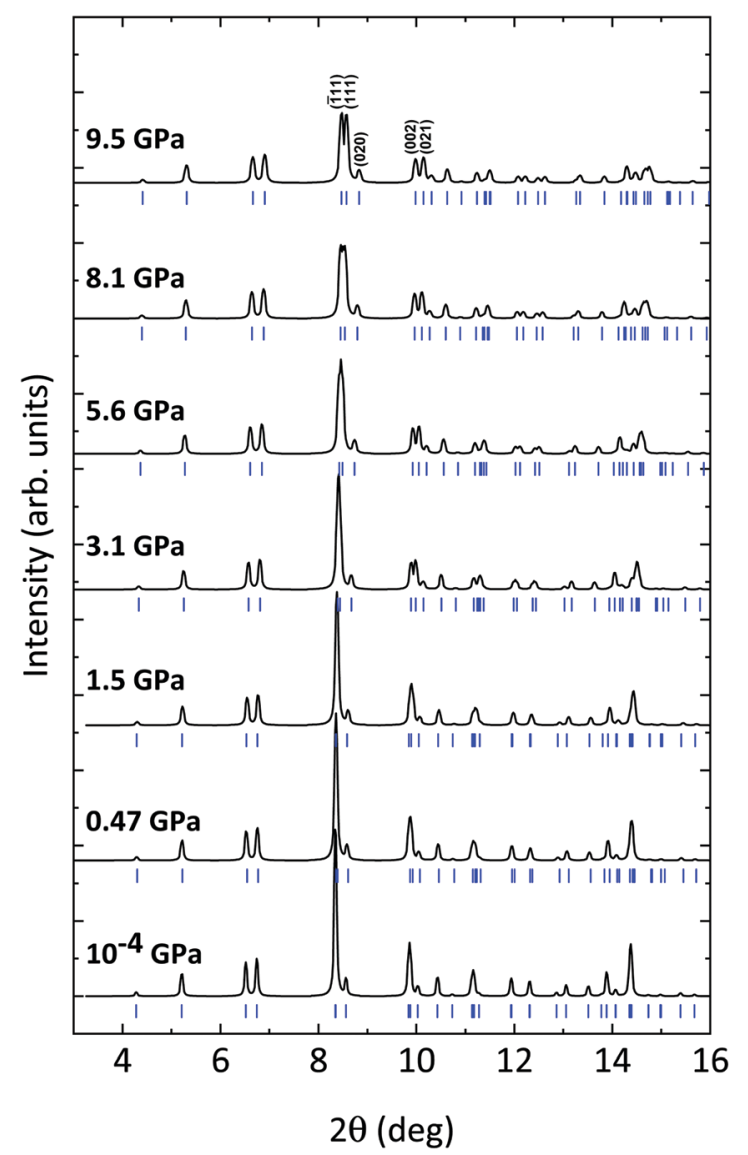

Fig. 3 Powder XRD patterns of $\mathrm{CoWO}_{4}$ at selected pressures. Blue ticks indicate the positions of the Bragg reflections. Reflections for which the splitting at high pressure is more evident have been indicated. 
Table 3 Linear functions describing the pressure dependence of unit-cell parameters of $\mathrm{CoWO}_{4}$. Intercept and slope are referred to the linear fits of the values of cell parameters vs. pressure

\begin{tabular}{llll}
\hline Parameter & Intercept & Slope & $k_{i}\left(10^{-3} \mathrm{GPa}^{-1}\right)$ \\
\hline$a$ & $4.669(2) \AA$ & $-0.0091(4) \AA_{\mathrm{GPa}}^{-1}$ & $1.95(9) \times 10^{-3} \mathrm{GPa}^{-1}$ \\
$b$ & $5.683(3) \AA$ & $-0.0182(7) \AA \mathrm{GPa}^{-1}$ & $3.2(1) \times 10^{-3} \mathrm{GPa}^{-1}$ \\
$c$ & $4.949(1) \AA$ & $-0.0073(2) \mathrm{APa}^{-1}$ & $1.48(4) \times 10^{-3} \mathrm{GPa}^{-1}$ \\
$\beta$ & $90.12(2) \mathrm{deg}$ & $0.089(4) \mathrm{deg} \mathrm{GPa}^{-1}$ & -
\end{tabular}

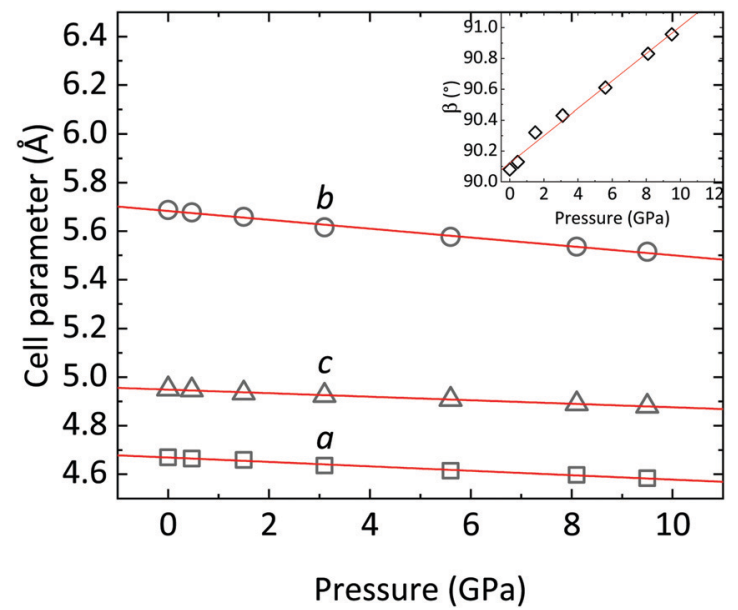

Fig. $4 \mathrm{CoWO}_{4}$ unit-cell parameters $a, b$ and $c$ as a function of pressure. The trend of the monoclinic $\beta$ angle is shown in the inset. Red lines are linear fits of the data.

increase their separation at higher pressure (see Fig. 3). In short, despite a steady increase of the monoclinic $\beta$ angle, no phase transitions are detected in the studied pressure range. As we will see in the following, this conclusion is corroborated by Raman spectroscopy and theoretical simulations.

In the following, the compressibility of $\mathrm{CoWO}_{4}$ is analyzed from the powder XRD data. Fig. 4 summarizes the variation of the cell parameters as a function of pressure. As anticipated, $a$, $b$, and $c$ smoothly decrease upon increasing pressure.

The axial compressibility of $\mathrm{CoWO}_{4},\left(k_{i}=\frac{1 \partial a_{i}}{a_{i}^{0} \partial P}\right.$, for the $a_{i}$ axis, $a_{i}^{0}$ being the cell parameter at ambient pressure) can be studied from the linear fits of the cell parameters $v s$. pressure. The values in Table 3 show that the compressibility along the $b$ axis is much higher than along the $a$ and $c$ axes. This anisotropic behavior, and the increase of the monoclinic angle, is commonly observed in wolframites, and has been reported previously for $\mathrm{MgWO}_{4}, \mathrm{CdWO}_{4}$ and $\mathrm{MnWO}_{4}$, among others. $^{36-38}$

A more rigorous insight on the axial compressibility of $\mathrm{CoWO}_{4}$ comes from the analysis of its compressibility tensor. For monoclinic structures, the tensor is symmetric and has only four non-zero components, whose values can be calculated using the analytical expressions given by Knight. ${ }^{39}$ These components for $\mathrm{CoWO}_{4}$ are summarized in Table 4, in which also the eigenvalues and eigenvectors of the compressibility tensor are shown. One of the eigenvectors is parallel to the
Table 4 Isothermal compressibility tensor coefficients, $\beta_{i j}$, their eigenvalues, $\lambda_{i}$, and eigenvectors, $\mathrm{ev}_{i}$, and angle of minimum direction of compression, $\psi$, for $\mathrm{CoWO}_{4}$

$\beta_{11}\left(\mathrm{GPa}^{-1}\right)$
$\beta_{22}\left(\mathrm{GPa}^{-1}\right)$
$\beta_{33}\left(\mathrm{GPa}^{-1}\right)$
$\beta_{13}=\beta_{31}\left(\mathrm{GPa}^{-1}\right)$
$\lambda_{1}\left(\mathrm{GPa}^{-1}\right)$
$\mathrm{ev}_{1}$
$\lambda_{2}\left(\mathrm{GPa}^{-1}\right)$
$\mathrm{ev}_{2}$
$\lambda_{3}\left(\mathrm{GPa}^{-1}\right)$
$\mathrm{ev}_{3}$
$\psi(\mathrm{deg})$

$1.952 \times 10^{-3}$

$3.209 \times 10^{-3}$

$1.471 \times 10^{-3}$

$7.726 \times 10^{-4}$

$2.5209 \times 10^{-3}$

$(0.80540,0,0.59273)$

$3.2095 \times 10^{-3}$

$(0,1,0)$

$9.02527 \times 10^{-4}$

$(-0.59273,0,0.8054)$

53.65

unique crystallographic $b$-axis, while the other two define a plane perpendicular to it. Compressibility is clearly anisotropic, as it varies between $9.0252 \times 10^{-4}$ and $3.2095 \times 10^{-3} \mathrm{GPa}^{-1}$ and the axis with the maximum compressibility is the unique $b$-axis ( $\beta_{22}$ component). On the other hand, the direction of minimum compressibility lies in the $a c$ plane, forming an angle of $53.65^{\circ}$ with the $c$ axis (from $c$ to $a$ ), corresponding to the crystallographic direction $[\overline{3}, 0,4] .{ }^{39}$ To first order, the isothermal compressibility of $\mathrm{CoWO}_{4}$ is given by the trace of the compressibility tensor, $\beta_{T}=\left(\sum_{i=3}^{3} \beta_{i i}\right)=6.63 \times 10^{-3} \mathrm{GPa}^{-1}, 39$ corresponding to an approximate value of the bulk modulus $B_{0}=150.76 \mathrm{GPa}$. For completeness, we also show the compressibility indicatrix, calculated using PASCal, in Fig. S1 (ESI $\dagger)^{40}$

An alternative estimate of the bulk modulus $B_{0}$ is obtained by fitting the experimental pressure-volume data to a 2ndorder Birch-Murnaghan EOS (Fig. 5), which gives a comparable result of $B_{0}=131(3)\left(V_{0}=131.43(10) \AA^{3}\right)$ GPa. These values are in line with the bulk moduli of other wolframites such as $\mathrm{MgWO}_{4}, \mathrm{MnWO}_{4}$, and $\mathrm{ZnWO}_{4}$ (see Table 5 for a comparison). ${ }^{36,41,42} \mathrm{Ab}$ initio simulations of the volume at ambient pressure agree within a $1 \%$ with the experimental values. Also, fitting a 2nd-order Birch-Murnaghan EOS on

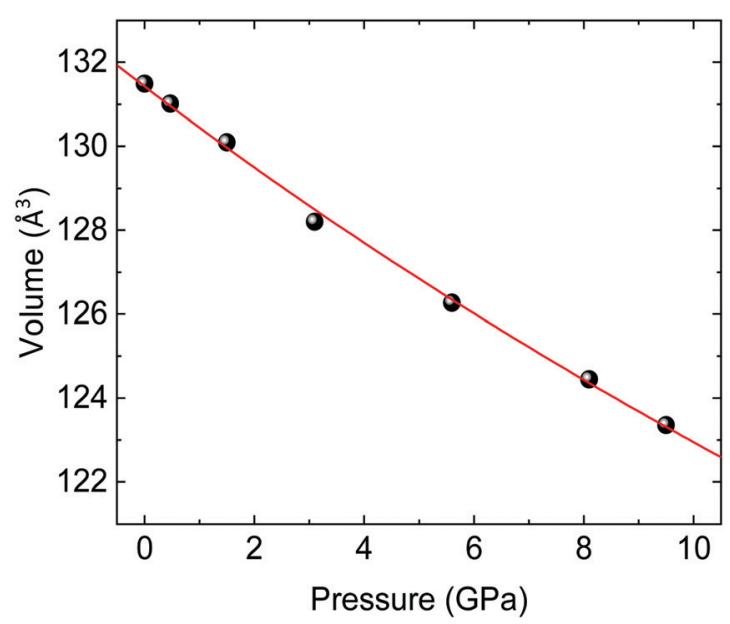

Fig. 5 Pressure-volume data for wolframite-type $\mathrm{CoWO}_{4}$ (black spheres) and fit with a 2nd-order Birch-Murnaghan EOS (red line). Errors are comparable to symbol size. 
Table 5 Values of the bulk modulus $\left(B_{0}\right)$, its derivative $\left(B_{0}{ }^{\prime}\right)$ and the volume at ambient pressure $\left(V_{0}\right)$ for $\mathrm{CoWO}_{4}$ and analogue wolframites. The experimental value of $B_{0}$ in parenthesis for $\mathrm{CoWO}_{4}$ has been estimated as the inverse of the trace of the compressibility tensor. The theoretical value of $B_{0}$ in parentheses for $\mathrm{CoWO}_{4}$ has been obtained directly by ab initio simulations

\begin{tabular}{|c|c|c|c|c|}
\hline Compound & $V_{0}\left(\AA^{3}\right)$ & $B_{0}(\mathrm{GPa})$ & $B_{0}^{\prime}$ & Ref. \\
\hline \multicolumn{5}{|l|}{$\mathrm{CoWO}_{4}$} \\
\hline Experiment & $131.43(10)$ & 131(3) (150.76) & 4 & This work \\
\hline $\begin{array}{l}\text { Theory } \\
\text { MgWO }_{4}\end{array}$ & $129.114(13)$ & $164.3(5)(161.15)$ & 4 & This work \\
\hline Experiment & 131.1(3) & $160(13)$ & $4.5(3)$ & 41 \\
\hline $\begin{array}{l}\text { Experiment } \\
\mathrm{MnWO}_{4}\end{array}$ & - & $144(3)$ & & 36 \\
\hline Experiment & - & $131(2)$ & 4 & 36 \\
\hline $\begin{array}{l}\text { Experiment } \\
\text { ZnWO }_{4}\end{array}$ & $138.8(2)$ & $145(3)$ & $4.3(2)$ & 42 \\
\hline Experiment & $132.9(5)$ & $145(6)$ & $6.6(9)$ & 41 \\
\hline
\end{tabular}

the theoretical pressure-volume data, as shown in Fig. S2 $(\mathrm{ESI} \dagger)$, gives a compatible, although slightly overestimated, value of $B_{0}$ (Table 5 ). It is interesting to notice that the experimental value of $B_{0}$ is very close to the one expected from the phenomenological rule proposed by Ruiz-Fuertes et al. $\left(B_{0}=137 \mathrm{GPa}\right)$, which relates the bulk modulus with the inverse of $\mathrm{A}-\mathrm{O}$ distance in $\mathrm{AWO}_{4}$ wolframites (A being a divalent element). ${ }^{41}$ It is noteworthy that our ab initio simulations predict that atomic positions are nearly constant across the studied pressure range, with a maximum variation around $0.3 \%$ over an increase of $1 \mathrm{GPa}$ in pressure for an oxygen atom. This value is comparable with the experimental uncertainty on the atomic positions in $\mathrm{CoWO}_{4}$ (see Table 1). Hence, in the following we will assume that atomic positions are constant in the entire pressure range. Therefore, the $\mathrm{CoO}_{6}$ and $\mathrm{WO}_{6}$ octahedra will have the same bulk modulus of the $\mathrm{CoWO}_{4}$ unit cell, given that their volume varies accordingly to the volume of the whole unit cell in the absence of atomic displacements. In turn, this implies that $\mathrm{CoO}_{6}$ and $\mathrm{WO}_{6}$ octahedra are equally compressible and contribute equally to the volume reduction of the unit cell under compression, unlike that observed in other $\mathrm{AWO}_{4}$ wolframites. $^{36}$

\section{Vibrational spectroscopy}

The Raman spectrum of monoclinic-type $\mathrm{CoWO}_{4}$ at ambient pressure, together with its evolution up to $10 \mathrm{GPa}$, is shown in Fig. 6. Group theory predicts a total of 18 Raman active modes for monoclinic-type $\mathrm{CoWO}_{4}$, with a mechanical representation at the $\Gamma$ point given by $\Gamma=8 \mathrm{~A}_{\mathrm{g}}+10 \mathrm{~B}_{\mathrm{g}} \cdot{ }^{43}$ All of the predicted modes have been detected in our experiments (Fig. 6 and Table 6), including one at $244 \mathrm{~cm}^{-1}$ which, to the best of our knowledge, had not been reported before. For $\mathrm{AWO}_{4}$ wolframites, active Raman modes can be classified into internal, high-frequency stretching modes of the $\mathrm{WO}_{6}$ octahedron, and external modes, originated by the motion of the A cation and the $\mathrm{WO}_{6}$ octahedron as a unit. ${ }^{38}$ The distribution of the modes in $\mathrm{CoWO}_{4}$ is the archetypical one for similar tungstates (4 modes above $600 \mathrm{~cm}^{-1}, 2$ isolated modes in the $500-550 \mathrm{~cm}^{-1}$ range,

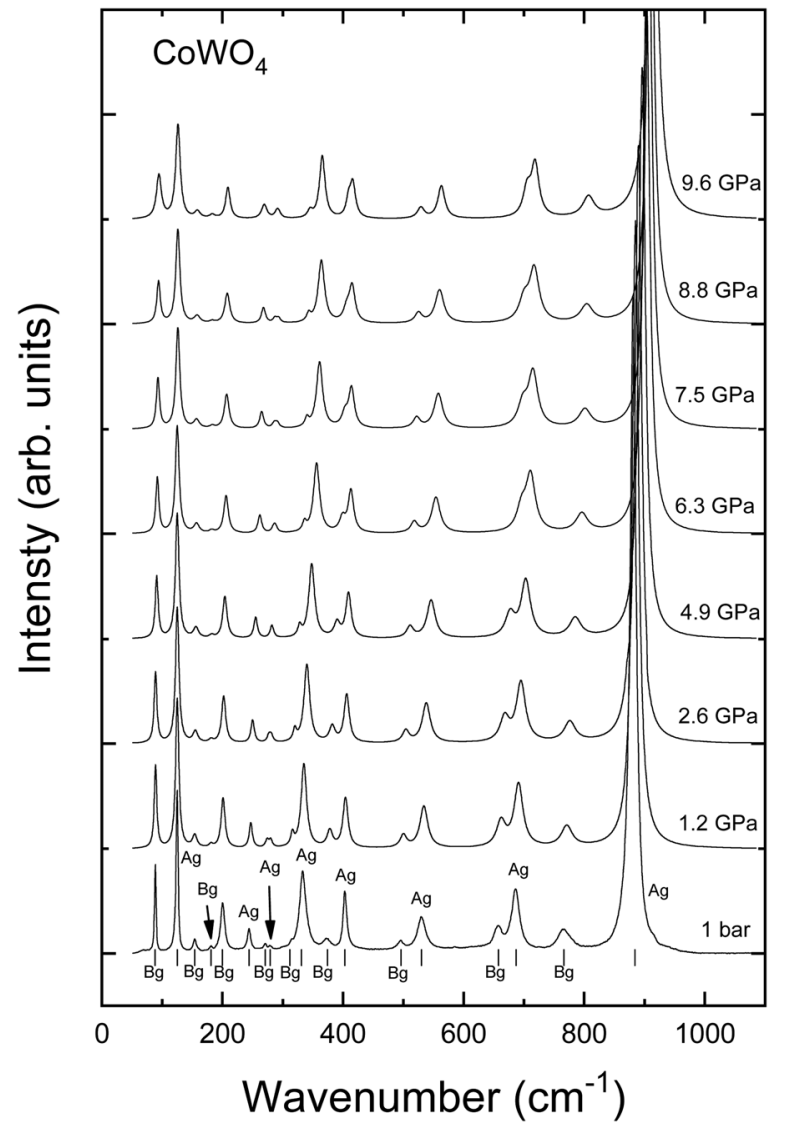

Fig. 6 Raman spectra of wolframite-type $\mathrm{CoWO}_{4}$ at ambient conditions (bottom) and at selected pressures. The symmetry and position of each peak are shown for the spectrum at ambient pressure (ticks).

Table 6 Symmetry, frequency under ambient conditions $\left(\omega_{0}\right)$, linear pressure coefficient and the Grüneisen parameter $(\mathrm{d} P / \mathrm{d} \omega$ and $\gamma$, respectively) of the Raman active phonons for $\mathrm{CoWO}_{4}$, as obtained from experiments and ab initio simulations. The asterisk indicates a phonon which had not been experimentally reported before

\begin{tabular}{|c|c|c|c|c|c|c|}
\hline \multirow{2}{*}{$\begin{array}{l}\text { Mode } \\
\text { Exp }\end{array}$} & \multicolumn{3}{|c|}{ Experiment } & \multicolumn{3}{|l|}{ Theory } \\
\hline & $\begin{array}{l}\omega_{0} \\
\left(\mathrm{~cm}^{-1}\right)\end{array}$ & $\begin{array}{l}\mathrm{d} \omega / \mathrm{d} P \\
\left(\mathrm{~cm}^{-1} \mathrm{GPa}^{-1}\right)\end{array}$ & $\gamma$ & $\begin{array}{l}\omega_{0} \\
\left(\mathrm{~cm}^{-1}\right)\end{array}$ & $\begin{array}{l}\mathrm{d} \omega / \mathrm{d} P \\
\left(\mathrm{~cm}^{-1} \mathrm{GPa}^{-1}\right)\end{array}$ & $\gamma$ \\
\hline $\mathrm{B}_{\mathrm{g}}$ & $88(1)$ & $0.66(4)$ & $0.89(7)$ & 92.83 & 0.79 & 1.11 \\
\hline$A_{g}$ & $125(1)$ & $0.12(3)$ & $0.12(3)$ & 128.42 & 0.74 & 0.75 \\
\hline $\mathrm{B}_{\mathrm{g}}$ & $154(1)$ & $0.45(4)$ & $0.35(4)$ & 157.27 & 1.03 & 0.86 \\
\hline $\mathrm{B}_{\mathrm{g}}^{\circ}$ & 181(1) & $0.27(3)$ & $0.18(2)$ & 183.66 & 0.60 & 0.43 \\
\hline $\mathrm{B}_{\mathrm{g}}$ & $200(1)$ & $0.93(3)$ & $0.56(4)$ & 189.19 & 0.54 & 0.37 \\
\hline$A_{g}$ & $244(1)^{*}$ & $2.74(10)$ & $1.34(9)$ & 222.88 & 2.70 & 1.59 \\
\hline $\mathrm{B}_{\mathrm{g}}$ & 271(1) & $2.24(13)$ & $0.99(8)$ & 277.89 & 2.61 & 1.23 \\
\hline$A_{g}$ & $278(1)$ & $1.26(13)$ & $0.54(6)$ & 294.77 & 0.70 & 0.31 \\
\hline $\mathrm{B}_{\mathrm{g}}^{\mathrm{s}}$ & $316(1)$ & $3.44(18)$ & $1.31(10)$ & 309.94 & 1.77 & 0.75 \\
\hline$A_{g}$ & $333(1)$ & $3.67(16)$ & $1.32(10)$ & 338.56 & 3.50 & 1.35 \\
\hline $\mathrm{B}_{\mathrm{g}}^{0}$ & $373(1)$ & $3.80(17)$ & $1.22(9)$ & 358.51 & 3.95 & 1.44 \\
\hline$A_{g}^{\circ}$ & $403(1)$ & $1.45(7)$ & $0.43(3)$ & 399.97 & 1.17 & 0.38 \\
\hline $\mathrm{B}_{\mathrm{g}}$ & 495(1) & $3.45(8)$ & $0.83(5)$ & 494.23 & 2.96 & 0.78 \\
\hline$A_{g}$ & $529(1)$ & $3.60(14)$ & $0.82(6)$ & 523.69 & 3.06 & 0.77 \\
\hline $\mathrm{B}_{\mathrm{g}}$ & $657(1)$ & $5.2(4)$ & $0.94(9)$ & 629.86 & 3.83 & 0.80 \\
\hline$A_{g}$ & $686(1)$ & $3.52(15)$ & $0.61(4)$ & 677.89 & 2.64 & 0.51 \\
\hline $\mathrm{B}_{\mathrm{g}}$ & $766(1)$ & $4.49(19)$ & $0.70(5)$ & 756.31 & 4.07 & 0.70 \\
\hline$A_{g}$ & $881(1)$ & $3.37(8)$ & $0.46(3)$ & 853.38 & 2.66 & 0.41 \\
\hline
\end{tabular}


and 12 modes below $\left.405 \mathrm{~cm}^{-1}\right) .{ }^{41}$ Nonetheless, for $\mathrm{CoWO}_{4}$, the frequency of some of the modes differs significantly between previous experimental reports. ${ }^{38,44-47}$ These discrepancies are mostly observed in the low-frequency range, i.e. mostly external modes are affected. It is thus reasonable to argue that these differences may arise from different preparation methods, which may impact sample purity and cell parameters.

All in all, the frequencies as obtained in our experiments and those calculated by $a b$ initio simulations are in good agreement, and the same can be said for the Grüneisen parameters, defined as $\gamma=\frac{B_{0}}{\omega_{0}} \frac{\partial \omega}{\partial P}$ (Table 6). Minor discrepancies between theory and experiments are not unusual for wolframite-type compounds. ${ }^{38}$ For $\mathrm{CoWO}_{4}$, the phonons which appear to be more sensitive to pressure are the one at $244 \mathrm{~cm}^{-1}$ and the three in the range from 316 to $373 \mathrm{~cm}^{-1}$, with a value of $\gamma$ well above 1 (Table 6). A similar situation is found in wolframite-type $\mathrm{MgWO}_{4}$, for which the highest Grüneisen parameters are low-frequency external modes within similar ranges. ${ }^{41}$ The data in Fig. 6 support the stability of wolframite-type $\mathrm{CoWO}_{4}$, as no qualitative differences are detectable among the Raman spectra at different pressure. Given that all phonons' linear pressure coefficients are positive (Table 6), no vanishing or splitting phonons are found in the studied pressure range, confirming the absence of structural transitions. As shown in Fig. 7, all Raman modes consistently blueshift upon compression.

Our $a b$ initio simulations support the experimental results. As shown in Fig. S3 (ESI $\dagger$ ), theoretical calculations correctly predict all phonons hardening under high pressure conditions. Therefore, no phonons become imaginary at any pressure point, ruling out the presence of phase transitions.

Wolframite-type $\mathrm{CoWO}_{4}$ also has 15 IR active phonons, whose mechanical representation at the $\Gamma$ point is $\Gamma=7 \mathrm{~A}_{\mathrm{u}}+$ $8 \mathrm{~B}_{\mathrm{u}}$ (excluding acoustic modes). ${ }^{43}$ Although experimental IR spectroscopy data for $\mathrm{CoWO}_{4}$ are not available by us at the moment, we have calculated the IR phonons and their evolution under pressure (see Fig. S4 and Table S2, ESI $\dagger$ ). The distribution of calculated IR modes is in good agreement with previous results. ${ }^{46}$ Similarly to the Raman modes, IR phonons generally harden with pressure. Only one $\mathrm{B}_{\mathrm{u}}$ mode around $247 \mathrm{~cm}^{-1}$ appears to have a small negative pressure coefficient. However, this cannot be interpreted as a sign of dynamical instability, as in the studied pressure range, all modes keep their real (positive) character.

The volumetric thermal expansion coefficient $\alpha$ of an oxide like $\mathrm{CoWO}_{4}$ can be obtained using a statistical thermodynamic approach by assuming that all the energy of a crystal resides in its vibrations. ${ }^{48,49}$ This has been successfully done in the past for $\mathrm{BaWO}_{4}$ using Raman and IR frequencies. ${ }^{49}$ Using this approach and the calculated frequencies and pressure dependences for different modes, we have estimated the thermal expansion for $\mathrm{CoWO}_{4}$ at ambient pressure and as a function of pressure. This information is relevant for the use of $\mathrm{CoWO}_{4}$ as an oxidation protection layer of ferritic stainless steel. ${ }^{50} \mathrm{We}$ found that at ambient pressure $\alpha=11 \times 10^{-6} \mathrm{~K}^{-1}$, in agreement with results reported from recent high-temperature XRD studies. ${ }^{50}$ Under compression, we have determined that the thermal expansion coefficient $\alpha$ of $\mathrm{CoWO}_{4}$ linearly decreases with pressure at a rate of $-2 \times 10^{-7} \mathrm{~K}^{-1} \mathrm{GPa}^{-1}, \alpha=9 \times 10^{-6} \mathrm{~K}^{-1}$ at $10 \mathrm{GPa}$. This behavior is similar to that reported for $\mathrm{BaWO}_{4} \cdot{ }^{49}$

\section{Elastic properties}

In the following we will discuss the elastic behavior of $\mathrm{CoWO}_{4}$. The monoclinic structure of $\mathrm{CoWO}_{4}$ only allows 13 independent non-zero components for the symmetric $6 \times 6$ elasticity matrix C, i.e. the diagonal $C_{i i}$ components $(i=1, \ldots, 6)$ plus $C_{12}$, $C_{13}, C_{15}, C_{23}, C_{25}, C_{35}, C_{46} \cdot{ }^{51}$ The values of these coefficients are shown in Table 7.

The $C_{i j}$ parameters of $\mathrm{CoWO}_{4}$ in Table 7 are roughly similar to those reported previously for $\mathrm{CdWO}_{4}$ and $\mathrm{ZnWO}_{4}$ and may be thus considered typical for $\mathrm{AWO}_{4}$ compounds ${ }^{52,53}$ even when they are calculated using an orthorhombic approximation for the structure of these compounds. ${ }^{54}$
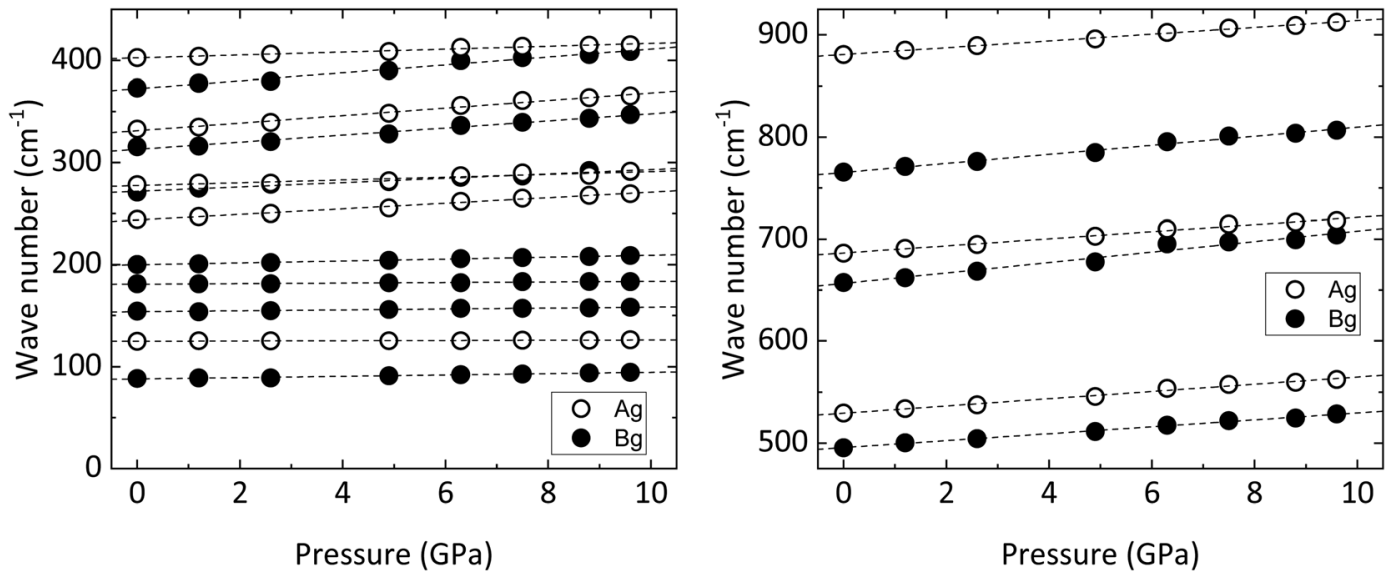

Fig. 7 Frequency of Raman modes vs. pressure for wolframite-type $\mathrm{CoWO}_{4}$ (circles). Dashed lines are the linear fits used for the calculation of the pressure coefficients and Grüneisen parameters. 
Table 7 Elastic constants $C_{i j}$ (in $\mathrm{GPa}$ ) at 1 bar for of wolframite-type $\mathrm{CoWO}_{4}$

\begin{tabular}{lllllllllllll}
\hline$C_{11}$ & $C_{22}$ & $C_{33}$ & $C_{44}$ & $C_{55}$ & $C_{66}$ & $C_{12}$ & $C_{13}$ & $C_{23}$ & $C_{15}$ & $C_{25}$ & $C_{35}$ & $C_{46}$ \\
\hline 222 & 252 & 307 & 77 & 83 & 71 & 125 & 116 & 116 & 11 & 3 & 29 & -9
\end{tabular}

The eigenvalues $\lambda_{1}(i=1, \ldots, 6)$ of the $C$ matrix, as shown in Table 8 , are all positive under ambient conditions, thus satisfying one of the four equivalent formulations of the Born elastic stability criterion. The positivity of all eigenvalues in fact, states a necessary and sufficient condition for the stability of the wolframite structure under ambient conditions. ${ }^{55}$

Under hydrostatic compression, the magnitudes which describe the elastic properties of a crystal are the components $B_{i j}$ of the elastic stiffness tensor $B$. These are related to the $C_{i j}$ coefficients by the following relationships:

$$
\begin{gathered}
B_{i i}=C_{i i}-P(i=1, \ldots, 6) ; \\
B_{12}=C_{12}+P, B_{13}=C_{13}+P, B_{23}=C_{23}+P ; \\
B_{15}=C_{15}, B_{25}=C_{25}, B_{35}=C_{35}, B_{46}=C_{46},
\end{gathered}
$$

where $P$ is the pressure. ${ }^{56}$ Under simulated hydrostatic compression, all of the $B_{i j}$ stiffness coefficients increase steadily, except for $B_{46}$ which presents a moderate decrease. On the other hand, $B_{44}$ and $B_{25}$ reach a maximum around 3 and $4 \mathrm{GPa}$, respectively, before decreasing slowly (Fig. 8a).

In the presence of an external load, such as non-zero hydrostatic compression, the equilibrium conditions for a crystal structure are given by the Born generalized criterion, which implies that the $B$ matrix must be definitely positive. ${ }^{56,57}$ This is equivalent to saying that the following six inequalities must be fulfilled:

$$
\begin{gathered}
M_{1}=B_{11}>0 \\
M_{2}=B_{11} B_{22}-B_{12}^{2}>0 \\
M_{3}=\left(B_{22} B_{33}-B_{23}^{2}\right) B_{11}-B_{33} B_{12}^{2}+2 B_{23} B_{12} B_{13}-B_{22} B_{13}{ }^{2}>0 \\
M 4=\mathrm{B}_{44}>0 \\
M_{5}=B_{12}{ }^{2} B_{35}^{2}-B_{33} B_{55} B_{12}{ }^{2}+2 B_{55} B_{12} B_{13} B_{23}-2 B_{12} B_{13} B_{25} B_{35} \\
-2 B_{12} B_{15} B_{23} B_{35}+2 B_{33} B_{12} B_{15} B_{25}+B_{13}^{2} B_{25}^{2}-B_{22} B_{55} B_{13}^{2} \\
-2 B_{13} B_{15} B_{23} B_{25}+2 B_{22} B_{13} B_{15} B_{35}+B_{15}^{2} B_{23}^{2}-B_{22} B_{33} B_{15}^{2}
\end{gathered}
$$

Table 8 Eigenvalues $\lambda_{1}$ (in GPa, $i=1, \ldots, 6$ ) of the elasticity matrix $C$ of wolframite-type $\mathrm{CoWO}_{4}$

\begin{tabular}{lr}
\hline$\lambda_{1}$ & 64.5 \\
$\lambda_{2}$ & 77.9 \\
$\lambda_{3}$ & 83.5 \\
$\lambda_{4}$ & 110.5 \\
$\lambda_{5}$ & 172.8 \\
$\lambda_{6}$ & 502.8
\end{tabular}

$$
\begin{gathered}
-B_{11} B_{55} B_{23}{ }^{2}+2 B_{11} B_{23} B_{25} B_{35}-B_{11} B_{33} B_{25}{ }^{2}-B_{11} B_{22} B_{35}{ }^{2}+ \\
B_{11} B_{22} B_{33} B_{55}>0 \\
M_{6}=B_{44} B_{66}-B_{46}{ }^{2}>0
\end{gathered}
$$

As shown in Fig. 8b, $M_{i}$ values are all positive across the entire pressure range and, plausibly, also well above $10 \mathrm{GPa}$. The wolframite structure of $\mathrm{CoWO}_{4}$ is thus expected to be stable even at pressures greater than $10 \mathrm{GPa}$. This result is compatible with our vibrational analysis, whose extrapolation excludes the appearance of phonons with negative frequency, and thus of dynamic instabilities, in the range immediately above $10 \mathrm{GPa}$.

Knowing the $C$ matrix and its inverse $S=C^{-1}$ (compliance tensor), elastic parameters such as the bulk modulus, $B_{0}$, the shear modulus, $G$, the Young's modulus $E$, and the Poisson ratio, $\nu$, can be calculated at ambient pressure, using the expression reported by Zhao et al. ${ }^{58}$ in both the Voigt and the Reuss approximations. These parameters are summarized in Table 9 for $\mathrm{CoWO}_{4}$ and all of them are in line with those already reported for $\mathrm{CdWO}_{4}$ and $\mathrm{ZnWO}_{4}{ }^{52-54}$

The average bulk modulus $B_{0}=164 \mathrm{GPa}$ calculated using the $C$ matrix is slightly overestimated with respect to the experimental value, even if such discrepancies are not uncommon for wolframites. ${ }^{38,53}$ Nonetheless, the bulk modulus calculated using the elastic matrix is in perfect agreement with theoretical values shown in Table 5 . Finally, the high $B_{0} / G$ ratio $(>2)$ indicates that $\mathrm{CoWO}_{4}$ is a malleable material. Elastic parameters as a function of pressure are resumed in Fig. S5 (ESI $\dagger$ ). While the bulk modulus increases uniformly under compression, the shear modulus slightly decreases, probably in connection with the increase of the monoclinic $\beta$ angle observed experimentally, which may also be the reason behind the decrease of the Young's modulus above 4 GPa (Fig. S5a-c, ESI $\dagger$ ). Although increasing with pressure, the Poisson ratio has a value $\nu<0.5$ across the studied pressure range (Fig. S5d, ESI $\dagger$ ), thus reflecting both the slightly anisotropic compressibility of wolframite-type $\mathrm{CoWO}_{4}$ (see results in the XRD section) and an increasing ionic character of the chemical bond. ${ }^{59,60}$ Finally, the bulk/shear ratio also increases under compression, indicating the high ductility of $\mathrm{CoWO}_{4}$ (Fig. S5d, ESI $\dagger$ ).

Given the scarcity of studies regarding the elastic properties of $\mathrm{AWO}_{4}$ wolframites, these results represent a valuable addition to the knowledge of those compounds, and we hope that they may stimulate more research on this subject, as significant trends may be thus established between the elastic properties of $\mathrm{AWO}_{4}$ materials and composition/external conditions (pressure/temperature).

\section{Electronic properties}

According to our calculations, wolframite $\mathrm{CoWO}_{4}$ is predicted to have two electronic gaps around $2.3 \mathrm{eV}$ under ambient conditions, which are very close in energy: a direct gap at the $\Gamma$ point and an indirect $\Gamma \rightarrow \mathrm{Z}$ gap (Fig. 9a). On the other hand, when $(\alpha h v)^{1 / 2}$ is plotted versus $h \nu$ (where $\alpha$ is the absorbance and $h \nu$ the energy of the incident light), a linear trend is found for energies above $2.3 \mathrm{eV}$ (Tauc plot, Fig. 10), meaning that the 

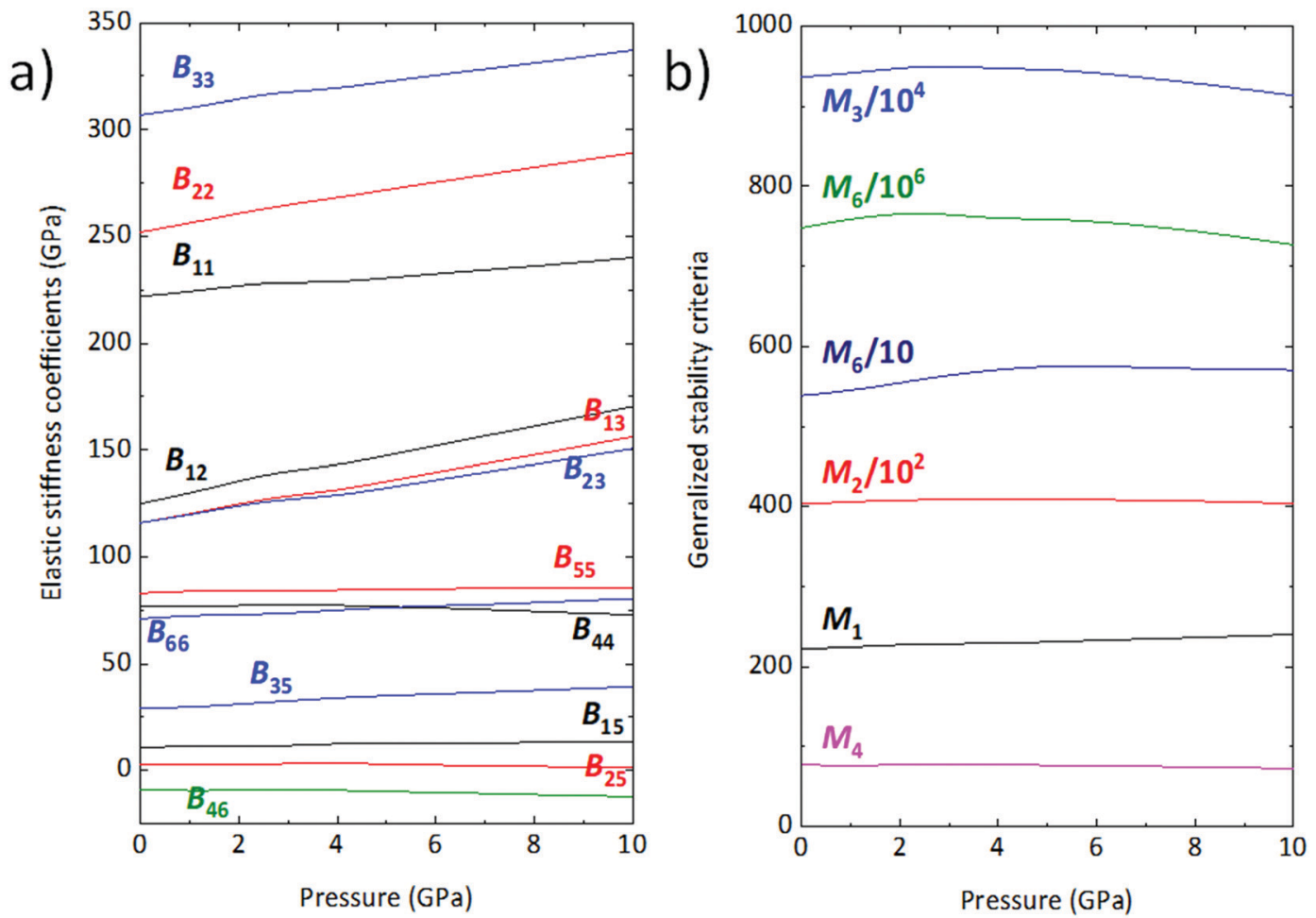

Fig. 8 (a) Elastic stiffness coefficients $B_{i j}$ as a function of pressure; (b) generalized stability criteria for wolframite-type $\mathrm{CoWO}_{4}$.

Table 9 Bulk modulus, $B$, shear modulus, $G$, the Young's modulus, $E$, and the Poisson's ratio, $\nu$, of wolframite-type $\mathrm{CoWO}_{4}$ at ambient pressure. The $B / G$ ratio is also shown

\begin{tabular}{llll}
\hline & Voight & Reuss & Average \\
\hline$B_{0}(\mathrm{GPa})$ & 166 & 162 & 164 \\
$G(\mathrm{GPa})$ & 75 & 71 & 73 \\
$E(\mathrm{GPa})$ & 194 & 186 & 190 \\
$\nu$ & 0.305 & 0.308 & 0.307 \\
$B_{0} / G$ ratio & 2.232 & 2.27 & 2.251 \\
\hline
\end{tabular}

fundamental gap in wolframite $\mathrm{CoWO}_{4}$ is of an indirect nature. This is not surprising, as $\mathrm{AWO}_{4}$ wolframites whose $\mathrm{A}^{2+}$ cation has unfilled $\mathrm{d}$ subshells have been shown to have indirect gaps. ${ }^{18,61}$

The band gap energy $E_{\mathrm{g}}$ of $\mathrm{CoWO}_{4}$, as extracted from the data in Fig. 10, is $E_{\mathrm{g}}=2.25(1) \mathrm{eV}$, in full agreement with theoretical calculations $\left(E_{\mathrm{g}}=2.33 \mathrm{eV}\right)$. These values suggest that the previous studies slightly overestimate $E_{\mathrm{g} .}{ }^{12,62}$ This can be understood considering that these values were determined either from indirect electrical measurements or from diffuse reflectance measurements in nanoparticles, two techniques that are less accurate that optical absorption. The value here determined for the band gap is also lower than those of analogue orthotungstates, which have gaps in the range of 2.37-4.06 eV (Table 10), $\mathrm{CoWO}_{4}$ being the wolframites with the lowest band gap so far. ${ }^{11,18}$ Interestingly, our result is in line with the predictions of Lacomba-Perales et al., which highlight a correlation between the band gap and the cationic
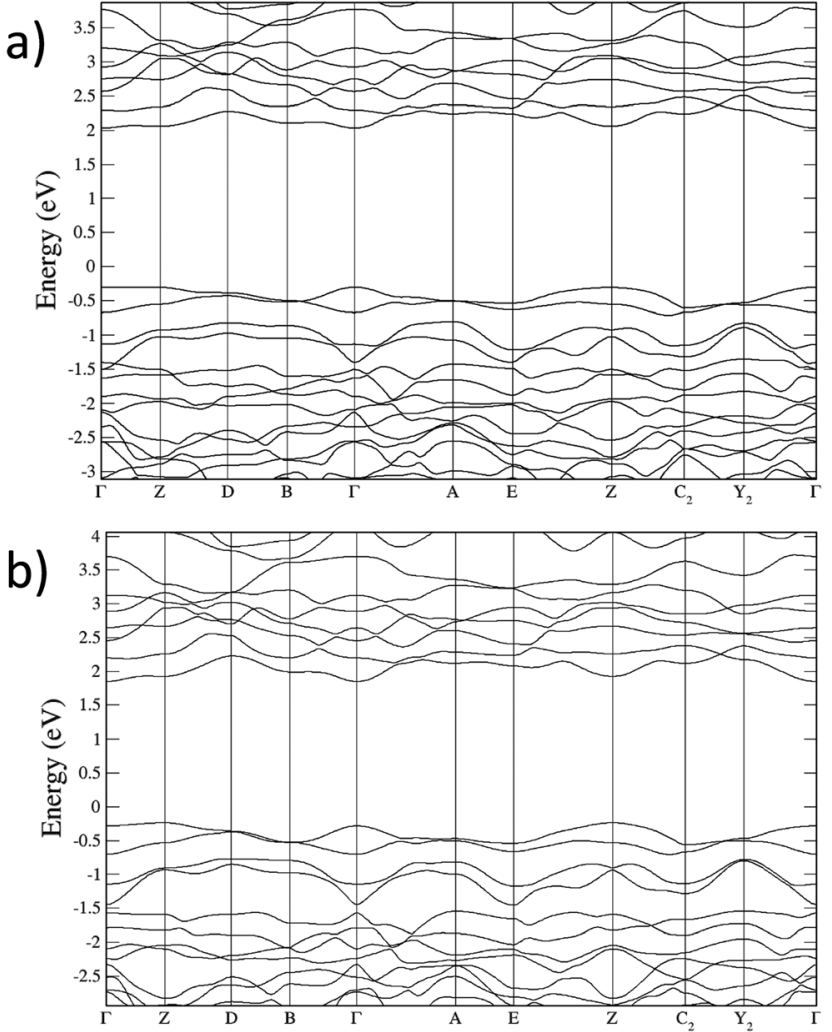

Fig. 9 Electronic band structure of wolframite $\mathrm{CoWO}_{4}$; (a) under ambient conditions, and (b) at $10 \mathrm{GPa}$. 


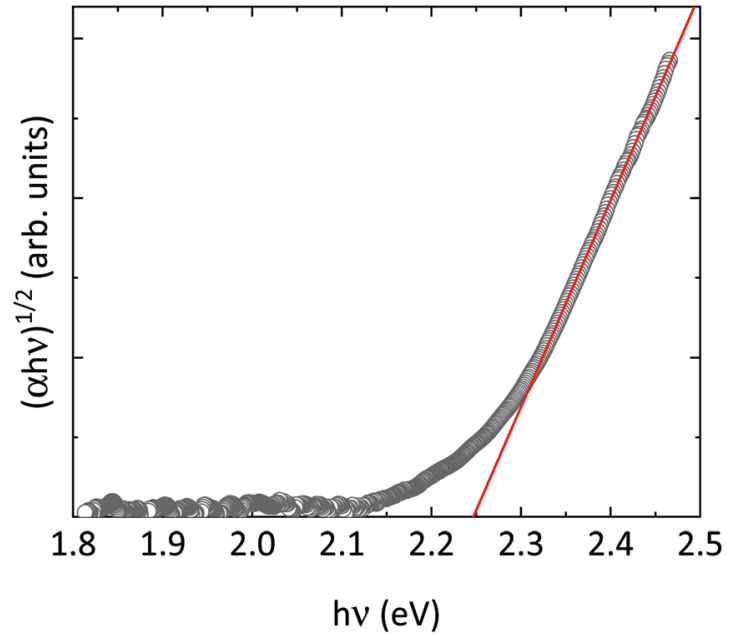

Fig. 10 Tauc plot of the absorbance spectrum of wolframite $\mathrm{CoWO}_{4}$ at ambient pressure. The fit of the linear region is shown in red.

radii in $\mathrm{AWO}_{4}$ wolframites. ${ }^{11}$ The value we determined for the band gap of $\mathrm{CoWO}_{4}(2.25(1) \mathrm{eV})$, makes it an excellent candidate as a semiconductor electrode for efficient visible light photolysis of water. $^{63}$

The small band gap of $\mathrm{CoWO}_{4}$ can be understood by analyzing the electronic contributions to its density of states (DOS). In $\mathrm{AWO}_{4}$ wolframites with large energy gaps, such as $\mathrm{MgWO}_{4}, \mathrm{ZnWO}_{4}$ and $\mathrm{CdWO}_{4}$, the bottom of the conduction band is dominated by $\mathrm{W} 5 \mathrm{~d}$ states hybridized with the $\mathrm{O} 2 \mathrm{p}$ state, while the upper part of the valence band is dominated by O $2 \mathrm{p}$ states slightly hybridized with $5 \mathrm{~d}$ states of $\mathrm{W}$. The contribution of the $\mathrm{A}^{2+}$ cation to both bands is negligible. On the other hand, for $\mathrm{MnWO}_{4}$, which has a narrower band gap, 2d states of $\mathrm{Mn}^{2+}$ contribute to both the valence and the conduction bands. ${ }^{18}$ Given the similar electronic configuration of Mn and $\mathrm{Co}$, it is thus fair to assume that for wolframite $\mathrm{CoWO}_{4}$, the $\mathrm{Co}^{2+} 3 \mathrm{~d}$ states are the reason behind the reduced band gap. Indeed, our calculations (Fig. 11a) show that under ambient conditions, the top of the valence band is contributed predominantly by $3 \mathrm{~d}$ states of $\mathrm{CO}^{2+}$ which still give a significant contribution to the bottom part of the conduction band along with $\mathrm{W} 5 \mathrm{~d}$ states and, to a lesser extent, $\mathrm{O} 2 \mathrm{p}$ states. Other $\mathrm{AWO}_{4}$ wolframites, with an $\mathrm{A}^{+2}$ having unfilled d states, such as $\mathrm{FeWO}_{4}$ and $\mathrm{NiWO}_{4}$, are also expected to exhibit a comparatively small band gap. ${ }^{11,61,64}$ This strengthens the hypothesis

Table 10 Band gap $E_{g}$ of wolframite-type $\mathrm{CoWO}_{4}$ with pressure coefficient as measured in this work and comparison with analogue wolframites (from ref. 18)

\begin{tabular}{llll}
\hline Compound $(\mathrm{eV})$ & $\begin{array}{l}\text { Theory } E_{\mathrm{g}} \\
(\mathrm{eV})\end{array}$ & $\begin{array}{l}\text { Experiments } E_{\mathrm{g}} \\
\left.\mathrm{GPa}^{-1}\right)\end{array}$ \\
\hline $\mathrm{MgWO}_{4}$ & 3.22 & 4.06 & 13.9 \\
$\mathrm{ZnWO}_{4}$ & 2.79 & 3.98 & 12.7 \\
$\mathrm{CdWO}_{4}$ & 2.91 & 4.02 & 12.0 \\
$\mathrm{MnWO}_{4}$ & 1.83 & 2.37 & -22.2 \\
$\mathrm{CoWO}_{4}$ & 2.33 & $2.25(1)$ & $-28.1(4)$
\end{tabular}
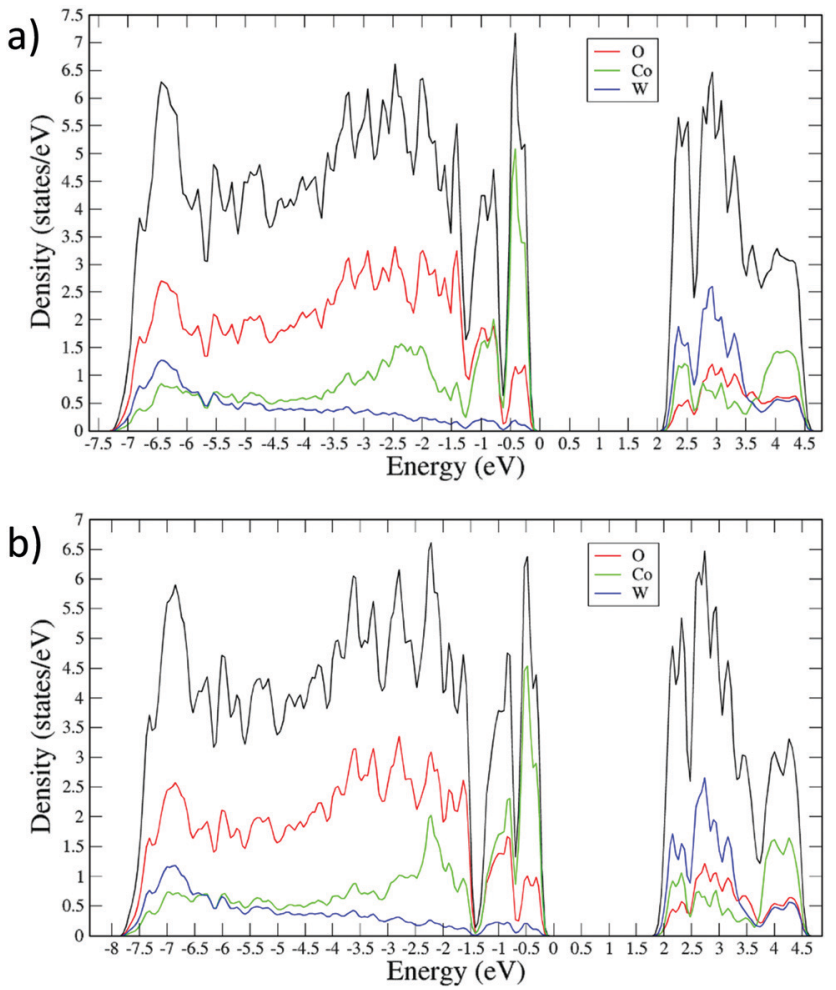

Fig. 11 Partial density of state of $\mathrm{CoWO}_{4}$ (a) under ambient conditions and (b) at a pressure of $10 \mathrm{GPa}$.

regarding the fundamental contribution of the open $d$ states to the band gap of these compounds.

In the following, we will discuss the behavior of the band gap of $\mathrm{CoWO}_{4}$ under high pressure conditions. Fig. 12 shows the $(\alpha h v)^{1 / 2} v s$. $h \nu$ Tauc plot of the absorption tail of $\mathrm{CoWO}_{4}$ at selected pressures. Same as in Fig. 10, all plots present a linear region above a certain energy $h \nu$ of the incident light, meaning that the band gap of wolframite $\mathrm{CoWO}_{4}$ retains its indirect

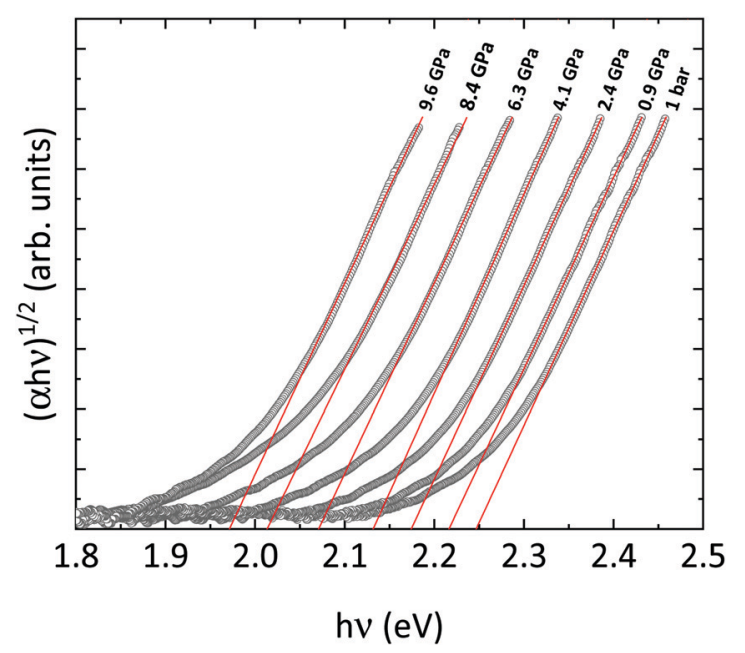

Fig. 12 Tauc plot of the absorbance spectrum of wolframite $\mathrm{CoWO}_{4}$ at selected pressures (shown above each curve). The fits of the linear regions are shown in red. 
character in this pressure range. This can be explained by the limited changes in the topology of the band structure of $\mathrm{CoWO}_{4}$ under compression (see Fig. 9a and b). On the other hand, it is evident how, unlike analogue wolframites, the band gap of $\mathrm{CoWO}_{4}$ closes with pressure (Fig. 13). Again, the absence of structural phase transitions in the studied pressure range is reflected in the smooth decrease of the band gap, without any discontinuous collapse. The decrease is linear, with a large negative pressure coefficient $\mathrm{d} E_{\mathrm{g}} / \mathrm{d} P=-28.1(4) \mathrm{meV} \mathrm{GPa}^{-1}$, a dependence on pressure even larger than that of wolframite $\mathrm{MnWO}_{4}\left(-22.2 \mathrm{meV} \mathrm{GPa}^{-1}\right)$. The experimental result is in perfect agreement with $a b$ initio calculations, which give a similar value of $-24.9(3) \mathrm{meV} \mathrm{GPa}^{-1}$ for the pressure coefficient. The relative contribution of $\mathrm{Co}, \mathrm{W}$ and $\mathrm{O}$ states to the DOS of $\mathrm{CoWO}_{4}$ remains unaffected in the studied pressure range, as shown in Fig. 11b. Nonetheless, features such as the two-peak shape structure in the -1.5 to $0 \mathrm{eV}$ range become more evident at high pressure. An analogous behavior is seen, again, in $\mathrm{MnWO}_{4}$, in which a similar feature is available in the DOS. ${ }^{18}$ The unfilled $\mathrm{Mn}^{2+} 3 \mathrm{~d}$ states are split by the octahedral crystal field into twofold $e_{\mathrm{g}}$ and threefold $\mathrm{t}_{\mathrm{g}}$ states, which give place to a two-peaks feature in the DOS of around $-0.75 \mathrm{eV}$ The splitting is enhanced by the pressure due to the shortening of the Mn-O bonds. ${ }^{18,36}$ Again, it is reasonable to expect a similar reason behind the behavior of the peak-like feature of the DOS of $\mathrm{CoWO}_{4}$ at the top of the valence band.

As mentioned, the decrease of the band gap with pressure is unusual for $\mathrm{AWO}_{4}$ wolframites. Akin to what was observed for $\mathrm{MnWO}_{4}$, in $\mathrm{CoWO}_{4}$ the unfilled 3d states of Co contribute to the bottom of the conduction band. These $d$ states are pushed down in energy by pressure, contrary to what happens for wolframites with filled d states such as $\mathrm{MgWO}_{4}, \mathrm{ZnWO}_{4}$, and $\mathrm{CdWO}_{4} \cdot{ }^{18,37}$ On the other hand, for all of the mentioned compounds, the top of the valence band is unaffected by pressure. The net result is a decrease (resp. increase) of the

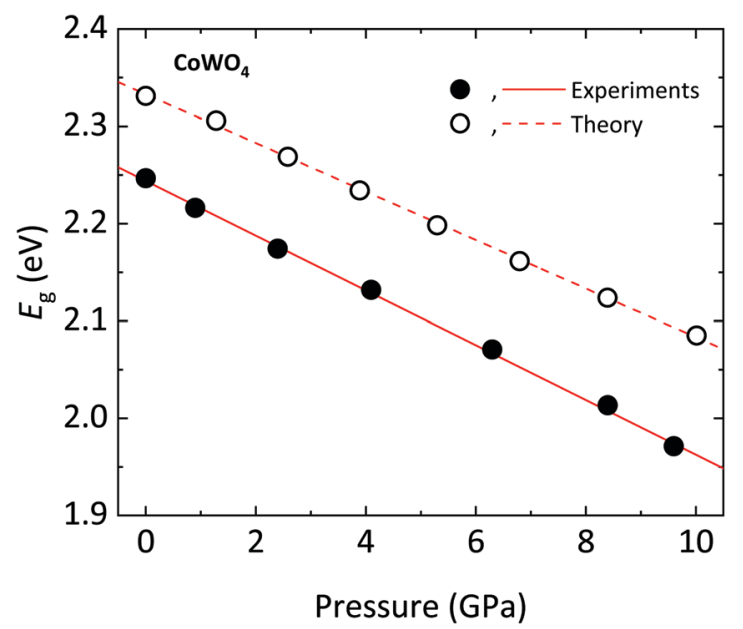

Fig. 13 Band gap $E_{g}$ of wolframite $\mathrm{CoWO}_{4}$ as a function of pressure (circles) with corresponding linear fits (lines). Closed (open) symbols and solid (dashed) lines correspond to experimental (theoretical) results. band gap with pressure for $\mathrm{AWO}_{4}$ wolframites with an open (resp. closed) d shell.

On the basis of our findings and previous results, a trend may thus be established, by which $\mathrm{AWO}_{4}$ wolframites with an $\mathrm{A}^{2+}$ cation with open $\mathrm{d}$ shell are expected to exhibit a comparatively small band gap, which further decreases under highpressure conditions. Further experimental studies are required to confirm this hypothesis.

To conclude the discussion of the electronic properties of $\mathrm{CoWO}_{4}$, we will comment on the effective mass of electrons and holes ( $m_{\mathrm{e}}$ and $m_{\mathrm{h}}$, respectively), which we have obtained from DFT calculations. This parameter is related to the carrier mobility, which directly affects the separation and diffusion rate of photo-induced charge carriers, one of the most important factors determining being the photocatalytic activity of a semiconductor. The effective mass of holes and electrons has been calculated from the second derivative of the energy with the wave vector. Due to the monoclinic structure of wolframite, the effective masses of carriers will be also anisotropic, being described by a non-diagonal tensor. ${ }^{65}$ For instance, it can be seen in Fig. 8 that the top valence band in the band structure of $\mathrm{CoWO}_{4}$ is more dispersive along $\mathrm{G}-\mathrm{A}$ and $\mathrm{G}-\mathrm{B}$ than along $\mathrm{G}-\mathrm{Z}$ and $\mathrm{G}-\mathrm{Y}_{2}$. A similar anisotropy is observed in the bottom conduction band of the band structure around the $Z$ point (the minimum of the conduction band). For practical purposes, an average effective mass can be defined as $m_{\mathrm{e}, \mathrm{h}}^{*}=\frac{3}{\sum_{i}^{n} 1 / m_{i}}[\mathrm{a}]$, where $m_{i}$ are the eigenvalues of the effective mass tensor. By following this procedure, we have determined that at ambient pressure $m_{\mathrm{e}}^{*}=2.4 m_{0}$ and $m_{\mathrm{h}}^{*}=3.3 m_{0}$. The first value is very high in comparison with the typical electron-mobility of semiconductors suggesting that $\mathrm{CoWO}_{4}$ has a low performance as an n-type semiconductor. In contrast, the second value is comparable to the hole-mobility of the best p-type semiconductors. ${ }^{66}$ These observations are consistent with the experimental observation that un-doped $\mathrm{CoWO}_{4}$ is a p-type semiconductor. $^{62}$ On the other hand, it is known that the relative ratio of effective mass determines the recombination rate of carriers. ${ }^{67}$ In our case $\frac{m_{\mathrm{e}}^{*}}{m_{\mathrm{h}}^{*}}=1.375$, which means that electrons and holes should easily recombine and show short lifetimes. Therefore, our study indicates that $\mathrm{CoWO}_{4}$ as the ideal band-gap energy to be used as a photocatalytic electrode; but also has the same limitations regarding photocurrent that a typical photocatalytic material as $\mathrm{BiVO}_{4}$ or $\mathrm{TiO}_{2}$ has. ${ }^{68,69}$

\section{Conclusions}

A multifaceted characterization was performed on wolframitetype $\mathrm{CoWO}_{4}$ under room conditions and at high pressures, of up to $10 \mathrm{GPa}$, by means of XRD, Raman spectroscopy, optical absorption spectroscopy, and $a b$ initio simulations. All these techniques agree in that $\mathrm{CoWO}_{4}$ is stable in the studied pressure range, as no signs of phase transitions could be detected. 
The bulk modulus of $\mathrm{CoWO}_{4}$ has been found to be in line with the values of other $\mathrm{AWO}_{4}$ wolframites, and its compressibility is equally anisotropic. The elastic constants of $\mathrm{CoWO}_{4}$ have been calculated and are found to be in line with those of analogue wolframites. For completeness, we have also discussed the elastic properties of $\mathrm{CoWO}_{4}$ under compression, as the characterization of the elastic behavior of wolframite is often neglected in the study of these compounds. The most intriguing experimental results are those regarding the electronic structure of $\mathrm{CoWO}_{4}$, which has been found to be an indirect semiconductor with a reduced band gap, of around $2.25 \mathrm{eV}$, when other wolframites such as $\mathrm{CdWO}_{4}, \mathrm{MgWO}_{4}$ and $\mathrm{ZnWO}_{4}$ have large direct gaps, with values around $4 \mathrm{eV}$. In addition, the band gap redshifts upon compression, something which may be beneficial for photocatalytic applications, and that has been seldom observed in $\mathrm{AWO}_{4}$ wolframites. These results are attributed to the open character of the $\mathrm{d}$ shell of $\mathrm{Co}^{2+}$, which contribute to both the bottom of the conduction band as well as to the top of the valence band. These allow us to draw broad conclusions as, by comparison with previous results, the electronic structure of wolframite $\mathrm{AWO}_{4}$ appears to be strongly influenced by the open or closed character of the $\mathrm{d}$ shell of the $\mathrm{A}^{2+}$ cation. As such, other wolframites, such as $\mathrm{FeWO}_{4}$ and $\mathrm{NiWO}_{4}$, are expected to behave similarly to $\mathrm{CoWO}_{4}$. In this respect, new studies and experiments are required to confirm significant trends in analogue compounds.

\section{Author contributions}

The manuscript was written through the contributions of all authors. All authors have approved the final version of the manuscript.

\section{Conflicts of interest}

There are no conflicts of interest to declare.

\section{Acknowledgements}

This research was supported by the Spanish Ministerio de Ciencia, Innovación y Universidades, the Spanish Research Agency, and the European Fund for Regional Development under Grant No. PID2019-106383GB-C41/43, FIS2017-83295-P and RED2018-102612-T and by Generalitat Valenciana under Grant Prometeo/2018/123 (EFIMAT). E. B would like to thank the University of Valencia for his "Attracció de Talent" postdoctoral contract (UV-INV_POSTDOC19-1026935). Powder X-ray diffraction experiments were performed at the Materials Science and Powder Diffraction beamline of ALBA Synchrotron (experiment no. 2016081784).

\section{References}

1 D. Errandonea and F. J. Manjón, Prog. Mater. Sci., 2008, 53, 711-773.
2 V. B. Mikhailik and H. Kraus, Phys. Status Solidi, 2010, 247, 1583-1599.

3 T. T. Monajemi, D. Tu, B. G. Fallone and S. Rathee, Med. Phys., 2006, 33, 1090-1100.

4 M. Mai and C. Feldmann, J. Mater. Sci., 2012, 47, 1427-1435.

5 R. C. Pullar, S. Farrah and N. M. Alford, J. Eur. Ceram. Soc., 2007, 27, 1059-1063.

6 V. Dusastre and D. E. Williams, J. Mater. Chem., 1999, 965-971.

7 C. M. Gonzalez, X. Du, J. L. Dunford and M. L. Post, Sens. Actuators, B, 2012, 173, 169-176.

8 K. Jothivenkatachalam, S. Prabhu, A. Nithya, S. Chandra Mohan and K. Jeganathan, Desalin. Water Treat., 2015, 54, 3134-3145.

9 H. Fu, C. Pan, L. Zhang and Y. Zhu, Mater. Res. Bull., 2007, 42, 696-706.

10 N. Hollmann, Z. Hu, T. Willers, L. Bohatý, P. Becker, A. Tanaka, H. H. Hsieh, H. J. Lin, C. T. Chen and L. H. Tjeng, Phys. Rev. B: Condens. Matter Mater. Phys., 2010, 82, 1-6.

11 R. Lacomba-Perales, J. Ruiz-Fuertes, D. Errandonea, D. Martínez-García and A. Segura, EPL, 2008, 83, 3.

12 G. V. Geetha, R. Sivakumar, Y. Kuroki, C. Gopalakrishnan and C. Sanjeeviraja, AIP Conf. Proc., 2020, 2265, 030094.

13 C. Ling, L. Q. Zhou and H. Jia, RSC Adv., 2014, 4, 24692.

14 S. M. AlShehri, J. Ahmed, T. Ahamad, P. Arunachalam, T. Ahmad and A. Khan, RSC Adv., 2017, 7, 45615-45623.

15 K. Hoang, M. Oh and Y. Choi, RSC Adv., 2018, 8, 4191-4196. 16 H. Cui, B. Li, Y. Zhang, X. Zheng, X. Li, Z. Li and S. Xu, Int. J. Hydrogen Energy, 2018, 43, 18242-18252.

17 M. I. Ahmed, A. Adam, A. Khan, A. U. Rehman, M. Qamaruddin, M. N. Siddiqui and M. Qamar, Mater. Lett., 2016, 183, 281-284.

18 J. Ruiz-Fuertes, S. López-Moreno, J. López-Solano, D. Errandonea, A. Segura, R. Lacomba-Perales, A. Muñoz, S. Radescu, P. Rodríguez-Hernández, M. Gospodinov, L. L. Nagornaya and C. Y. Tu, Phys. Rev. B: Condens. Matter Mater. Phys., 2012, 86, 1-9.

19 F. Fauth, I. Peral, C. Popescu and M. Knapp, Powder Diffr., 2013, 28, S360-S370.

20 H. K. Mao, P. M. Bell, J. W. Shaner and D. J. Steinberg, J. Appl. Phys., 1978, 49, 3276-3283.

21 C. Prescher and V. B. Prakapenka, High Pressure Res., 2015, 35, 223-230.

22 W. Kraus and G. Nolze, J. Appl. Crystallogr., 1996, 29, 301-303.

23 K. Momma and F. Izumi, J. Appl. Crystallogr., 2011, 44, 1272-1276.

24 P. Hohenberg and W. Kohn, Phys. Rev., 1964, 136, B864-B871.

25 G. Kresse and J. Furthmüller, Comput. Mater. Sci., 1996, 6, 15-50.

26 G. Kresse and J. Hafner, Phys. Rev. B: Condens. Matter Mater. Phys., 1993, 47, 558-561.

27 P. E. Blöchl, Phys. Rev. B: Condens. Matter Mater. Phys., 1994, 50, 17953-17979. 
28 J. P. Perdew, A. Ruzsinszky, G. I. Csonka, O. A. Vydrov, G. E. Scuseria, L. A. Constantin, X. Zhou and K. Burke, Phys. Rev. Lett., 2008, 100, 136406.

29 S. L. Dudarev, G. A. Botton, S. Y. Savrasov, C. J. Humphreys and A. P. Sutton, Phys. Rev. B: Condens. Matter Mater. Phys., 1998, 57, 1505-1509.

30 P. Kristine, Materials Data on CoWO4, https://materialspro ject.org/materials/mp-19092/.

31 A. Togo and I. Tanaka, Scr. Mater., 2015, 108, 1-5.

32 N. Chetty, A. Muoz and R. M. Martin, Phys. Rev. B: Condens. Matter Mater. Phys., 1989, 40, 11934-11936.

33 Y. Le, Page and P. Saxe, Phys. Rev. B: Condens. Matter Mater. Phys., 2002, 65, 104104.

34 H. Weitzel, Z. Kristallogr. - New Cryst. Struct., 1976, 144, 238-258.

35 S. Klotz, J.-C. Chervin, P. Munsch and G. Le Marchand, J. Phys. D: Appl. Phys., 2009, 42, 075413.

36 J. Macavei and H. Schulz, Z. Kristallogr. - Cryst. Mater., 1993, 207, 193-208.

37 D. Errandonea and J. Ruiz-Fuertes, Crystals, 2018, 8, 1-19.

38 J. Ruiz-Fuertes, D. Errandonea, S. López-Moreno, J. González, O. Gomis, R. Vilaplana, F. J. Manjón, A. Muñoz, P. RodríguezHernández, A. Friedrich, I. A. Tupitsyna and L. L. Nagornaya, Phys. Rev. B: Condens. Matter Mater. Phys., 2011, 83, 1-11.

39 K. S. Knight, Phys. Chem. Miner., 2010, 37, 529-533.

40 M. J. Cliffe and A. L. Goodwin, J. Appl. Crystallogr., 2012, 45, 1321-1329.

41 J. Ruiz-Fuertes, S. López-Moreno, D. Errandonea, J. PellicerPorres, R. Lacomba-Perales, A. Segura, P. RodríguezHernández, A. Muoz, A. H. Romero and J. González, J. Appl. Phys., 2010, 107, 0-10.

42 J. Ruiz-Fuertes, A. Friedrich, O. Gomis, D. Errandonea, W. Morgenroth, J. A. Sans and D. Santamaría-Pérez, Phys. Rev. B: Condens. Matter Mater. Phys., 2015, 91, 1-7.

43 E. Kroumova, M. I. Aroyo, J. M. Perez-Mato, A. Kirov, C. Capillas, S. Ivantchev and H. Wondratschek, Phase Transitions, 2003, 76, 155-170.

44 H. V. S. B. Azevêdo, R. A. Raimundo, L. S. Ferreira, M. M. S. Silva, M. A. Morales, D. A. Macedo, U. U. Gomes and D. G. L. Cavalcante, Mater. Chem. Phys., 2020, 242.

45 R. L. Moreira, R. M. Almeida, K. P. F. Siqueira, C. G. Abreu and A. Dias, J. Phys. D: Appl. Phys., 2015, 49, 45305.

46 E. C. Xiao, M. Liu, Q. Ren, Z. Cao, M. Guo, G. Dou, Z. M. Qi and F. Shi, Ceram. Int., 2020, 46, 15705-15708.

47 M. Salamanca, Y. E. Licea, A. Echavarría, A. C. Faro and L. A. Palacio, Phys. Chem. Chem. Phys., 2009, 11, 9583-9591. 48 A. Chopelas, Phys. Earth Planet. Inter., 1996, 98, 3-15.
49 R. Lacomba-Perales, D. Martinez-Garciá, D. Errandonea, Y. Le Godec, J. Philippe and G. Morard, High Pressure Res., 2009, 29, 76-82.

50 L. Gan, T. Nishimura, S. A. Sheikh, I. Saeki and H. Murakami, Corros. Sci., 2020, 176, 109037.

51 J. F. Nye, Physical properties of crystals. Their representation by tensors and matrices, Oxford University Press, Oxford, UK, 1985.

52 D. L. Shruthi, A. Jagannatha Reddy, G. N. Anil Kumar, C. K. Jayasankar and R. Hari Krishna, Mater. Res. Express, 2019, 6, 12.

53 M. G. Brik, V. Nagirnyi and M. Kirm, Mater. Chem. Phys., 2013, 137, 977-983.

54 Y. V. Pisarevskii, I. M. Silvestrova, R. Voszka, Péter, I. Földvári and J. Janszky, Phys. Status Solidi, 1988, 107, 161-164.

55 F. Mouhat and F. X. Coudert, Phys. Rev. B: Condens. Matter Mater. Phys., 2014, 90, 4-7.

56 G. Grimvall, B. Magyari-Köpe, V. Ozoliņš and K. A. Persson, Rev. Mod. Phys., 2012, 84, 945-986.

57 D. C. Wallace, Phys. Rev., 1967, 162, 776-789.

58 X. S. Zhao, S. L. Shang, Z. K. Liu and J. Y. Shen, J. Nucl. Mater., 2011, 415, 13-17.

59 G. N. Greaves, A. L. Greer, R. S. Lakes and T. Rouxel, Nat. Mater., 2011, 10, 823-837.

60 A. Muñoz and P. Rodríguez-Hernández, Crystals, 2018, 8, 10-12.

61 S. Rajagopal, V. L. Bekenev, D. Nataraj, D. Mangalaraj and O. Y. Khyzhun, J. Alloys Compd., 2010, 496, 61-68.

62 R. Bharati, R. A. Singh and B. M. Wanklyn, J. Mater. Sci., 1981, 16, 775-779.

63 S. A. Razek, M. R. Popeil, L. Wangoh, J. Rana, N. Suwandaratne, J. L. Andrews, D. F. Watson, S. Banerjee and L. F. J. Piper, Electron. Struct., 2020, 2, 023001.

64 M. A. P. Almeida, L. S. Cavalcante, C. Morilla-Santos, P. N. L. Filho, A. Beltrán, J. Andrés, L. Gracia and E. Longo, Mater. Charact., 2012, 73, 124-129.

65 D. J. Moss, E. Ghahramani, J. E. Sipe and H. M. van Driel, Phys. Rev. B: Condens. Matter Mater. Phys., 1990, 41, 1542-1560.

66 G. Hautier, A. Miglio, G. Ceder, G.-M. Rignanese and X. Gonze, Nat. Commun., 2013, 4, 2292.

67 H. Zhang, L. Liu and Z. Zhou, Phys. Chem. Chem. Phys., 2012, 14, 1286-1292.

68 Y. Yamada and Y. Kanemitsu, Appl. Phys. Lett., 2012, 101, 133907.

69 K. Ding, B. Chen, Y. Li, Y. Zhang and Z. Chen, J. Mater. Chem. A, 2014, 2, 8294-8303. 